\title{
Trading volume and returns relationship in SET50 index futures market
}

\author{
Sirirat Thammasiri ${ }^{1,2}$, Suluck Pattarathammas ${ }^{1}$ \\ (1. Thammasat Business School, Thammasat University, Bangkok 10200, Thailand; \\ 2. Government Pension Fund, Bangkok 10500, Thailand)
}

\begin{abstract}
This study investigates the relationship between trading volume and returns in SET50 index Futures market in the period from April 2006 to December 2008 using 653 observations. From previous studies, we include three methodologies namely the GARCH model, the Generalized Method of Moments (GMM) to estimate systems of equations and the Granger causality test to investigate the relationship more thoroughly. In addition, we introduce the lagged volume as a new explanatory variable in the GARCH model. Overall, the results show the significant contemporaneous and dynamic relationships between trading volume and returns volatility which support the sequential information arrival hypothesis and imply some degree of market inefficiency. The results from this study also show that past information of trading volume can be used to improve the prediction of price volatility. Therefore, regulators and traders could include past information of trading volume of SET50 index futures in tracking and monitoring the market volatility level and the investment risk in order to make a timely decision.
\end{abstract}

Key words: futures returns; futures trading volume; GARCH; GMM and sequential information arrival

\section{Introduction}

The relationship between trading volume and returns of financial assets has been studied in various financial markets for a long time, as trading volume was used to be a proxy of information flow to the financial markets. The early researches about this relationship can be grouped into 2 main categories which are the positive relationship between trading volume and returns (or price change) and the positive relationship between trading volume and price volatility (measured by the absolute returns or the absolute of price change). The positive relationship between trading volume and returns implies that trading volume is higher when the price increases than when the price decreases as stated in the "costly short sales hypothesis" (Karpoff, 1988). The hypothesis suggested that the positive correlation between trading volume and returns is a result of institutional rules that raise the cost of selling short. The costly short sales hypothesis was also supported by many previous empirical studies (Karpoff, 1987) in both stock and bond markets, where short position was more costly than long position. However, this relationship was absent in futures markets, which have no short sale constraint. This study will investigate the relationship between trading volume and returns in Thai stock index futures markets with the focus on the relationship between trading volume and price volatility (absolute returns) in futures market. The relationship between trading volume and price volatility was generally explained by two leading hypotheses, the mixture of distribution hypothesis (MDH) and the sequential information arrival hypothesis (SIA).

Sirirat Thammasiri, MSc. in finance, Government Pension Fund, Thammasat Business School, Thammasat University; research fields: stock index futures, market efficiency.

Suluck Pattarathammas, D.B.A. (Finance), assistant professor, corresponding author, Thammasat Business School, Thammasat University; research fields: fixed-income security, risk management, international finance. 
The mixture of distribution hypothesis (MDH) proposes that price volatility and trading volume should have a positive relationship because they jointly depend on the same mixing variable, which is assumed to be new information arriving at the market. So, under the $\mathrm{MDH}$, price and trading volume change contemporaneously due to this new information. On the other hand, sequential information arrival hypothesis assumes that new information sequentially arrives to each trader in the market, and then each trader will trade according to the information signal until all traders have the same set of information and the market reaches the new equilibrium. The main difference between MDH and SIA is the speed of adjustment towards new equilibrium, when new information arrives at the market. Under the $\mathrm{MDH}$, the new market equilibrium is reached immediately, while the SIA allows some period of adjustment before reaching the new equilibrium.

Both MDH and SIA predict the positive contemporaneous relationship between trading volume and absolute returns. However, the SIA hypothesis further suggests the dynamic relationship between trading volume and absolute returns in the way that the past trading volume gives information about current absolute returns and vice versa (McMillan \& Speight, 2002). This study will investigate both contemporaneous and dynamic relationship between trading volume and price volatility in SET50 index futures and will provide further evidence to support (or against) either hypothesis.

The studies about the relationship between trading volume and price are related to the market structure, including the rate of information flow to the market, how information is disseminated in the market and the size of the market. So, empirical study on this topic will provide information about market structure and also the level of information efficiency of the market. Moreover, empirical evidence about the relationship between trading volume and returns will be beneficial for the future event studies that use trading volume and returns as variables to test the information content of an event. According to Karpoff (1987), trading volume can be used to investigate whether an event has information content and whether investors interpret the information in the same way or not.

In case of Thailand, Chiradatesakunvong (2004) and Chatrirat (2006) investigated the relationship between trading volume and price (returns) in the equity market and found the positive results. However, there is no similar study for Thai futures market. Moreover, both MDH and SIA assume the symmetric effect for the positive and the negative price changes. This assumption is more appropriate for futures markets which have no short sale constraint. Therefore, the study about the relationship between trading volume and price volatilities in Thai futures market will give additional evidence either to support or to be against those hypotheses.

The relationship trading volume and price volatilities had been studied extensively in the past. Using GARCH model, Lamoureux and Lastrapes (1990) and Sharma, et al (1996) tested whether trading volume can explain GARCH effect in returns volatility in stock market using data of actively traded stocks and New York Stock Exchange index (NYSE) respectively. Floros and Vougas (2007) used GARCH and GMM method to investigate the relationship between trading volume and returns in Greek stock index futures market and found that trading volume was used as the indicator of prices. Ciner (2002) applied the GMM to estimate the system of equations that show the contemporaneous relations between absolute returns and trading volume, and performed the Granger causality test in the context of VAR model to investigate the dynamic relationship between trading volume and returns, and also examined whether past information of trading volume and returns can be used to improve the prediction of another.

This study will be the first one that not only investigates the relationship between trading volume and price volatilities, but also examines whether past trading volume contains information that is useful for predicting the price movement in Thai futures market by incorporating 3 methodologies which are the GARCH model, the 
simultaneous equations estimated from GMM and also the Granger causality test in the context of VAR approach.

Thailand futures exchange (TFEX) was established in May 2004, as a derivatives exchange and then launched its first product, SET50 index futures, in April 2006. The SET50 index futures is a futures contract which has the SET50 index as an underlying. The SET50 index is calculated from the stock prices of top 50 listed companies in stock exchange of Thailand (SET) in terms of large market capital, high liquidity and compliance with the requirement of SET. The SET50 index futures has 4 series of contract (which expire in March, June, September and December). As the futures market of Thailand has just been developed in the last few years, so there are still limit studies about Thai futures market. This study will provide new knowledge about Thai futures market characteristics such as the impact of new information on the futures price volatility, and benefit financial managers and investors dealing in TFEX as it will give the estimation results about the relationship between trading volume and price volatilities.

This paper consists of 5 sections. The first one is the introduction of this study; Section 2 provides the review of previous researches on this area of study; Section 3 explains the theoretical framework, methodology and data used; Section 4 and 5 present the empirical results and the conclusion respectively.

\section{Literature review}

Most of the previous empirical results found the positive relationship between trading volume and returns volatility. There are two leading hypotheses that attempt to explain these relationships.

Firstly, the mixture of distribution hypothesis (MDH) (Clark, 1973; Tauchen \& Pitts, 1983) assumes that price changes follow a mixture of normal distribution with the rate of information arrival to the market as the mixing variable. The MDH suggests that price changes and trading volume have the joint relationship to the same information. It implies that trading volume has positive contemporaneous relationship to the returns volatility.

The sequential information arrival hypothesis (Copeland, 1976) argues that individuals receive new information sequentially in random order and response to the information at that time, while trading volume is a positive logarithm function of number of traders and strength of new information which is the size of change in traders' demand curve. According to the sequential information arrival hypothesis, there will be a positive contemporaneous correlation between trading volume and absolute returns and the dynamic relationship implies that the past information can be used for the prediction of current trading volume and price volatility.

The major empirical studies about the relationship between trading volume and price are shown below.

Using generalized autoregressive conditional heteroskedasticity (GARCH) model to investigate the effect of trading volume on conditional variance of returns, Lamoureux and Laptrapes (1990) examined the implication of the MDH and argued that trading volume could be used as a proxy for the rate of information flows into the market. The result of their study suggested that the variance of daily returns is heteroskedasticity and positively related to the rate of daily information arrival. They applied GARCH model to daily returns of 20 traded stocks and found that the GARCH effect of most stock returns tended to disappear and the persistence of volatility, measured by a sum of the covariance of ARCH terms was reduced when trading volume was included in the variance equation; However, GARCH effect for some stocks remained significant. These findings supported the joint hypothesis that the GARCH effect in stock returns was a result of information arrival and trading volume could be a good proxy for the rate of information flows. Sharma, et al (1996) extended the work of Lamoureux and Laptrapes (1990) by examining how well the GARCH effect in market returns were explained by market 
volume by using data of the New York Stock Exchange Index (NYSE). They found that although trading volume had positive and significant relationship to the market returns, GARCH effect was still not completely eliminated after trading volume was included in the model. Girma and Mougue (2002) investigated the source of volatility in petroleum futures spreads using GARCH model and found that contemporaneous and lagged volume as well as open interests provided significant explanation for futures spread volatility. Floros and Vougas (2007) examined the relationship between trading volume and returns (volatility) in Greek stock index futures market-FTSE/ASE-20 contracts and FTSE/ASE40 contracts. They applied both the GARCH and the GMM system estimation and found that trading volume significantly explained GARCH effect for FTSE/ASE-20 but not for the FTSE/ASE-40.

Using the generalized method of moment (GMM) approach to estimate the simultaneous equations to of trading volume and price volatility, most of previous researchers found significantly positive contemporaneous relationship between trading volume and price volatility, but they found negative relationship between lagged trading volume and price volatility. Gwilym, et al (1999) investigated the relationship between volatility and volume for stock index, the short term interest rate and government bond futures contracts traded on the London international financial futures and option exchange (LIFFE). The result from their study showed that trading volume had positive contemporaneous relationship to the price volatility while the lags of trading volume had negative relationship to price volatility. Wang and Yau (2000) examined the relationship among trading volume, the bid-ask spread and price volatility on four financial and metal futures contracts in the Chicago mercantile exchange (CME) and the commodity exchange (COMEX) using GMM to estimate three-equation structural model. They also found the positive contemporaneous relationship between trading volume and price volatility. Similar results were supported by Ciner (2002) who investigated the relationship between trading volume and absolute returns in Tokyo commodities futures market (TOCOM). The significant positive contemporaneous relationship between trading volume and absolute returns found in most of studies suggests that trading volume and absolute returns are endogenous and respond to the same exogenous variable, assuming information arrival as suggested by the MDH. On the other hand, the significant negative relationship between trading volume and absolute returns implies that past information of trading volume can be used to explain current price volatility supporting the sequential information arrival hypothesis and it also implies that market is inefficient.

Another frequently used method to investigate the dynamic relationship between trading volume and (absolute) returns is the Granger causality test. The Granger causality test in the context of VAR model was employed to examine whether lags of trading volume and (absolute) returns contain useful information for the prediction of another variable, as implied by the SIA. Gwilym, et al (1999) used the Granger causality test to investigate causal relationship between volatility and volume of futures contracts traded on LIFFE and the result showed bi-directional causality which supported the SIA. McMillan and Speight (2002) extended the previous study by performing the Granger causality test using variety of intra-day frequency data from LIFFE futures market and the result also supported the SIA. Ciner (2002) investigated the dynamic relationship between volume and price change by using the Granger causality test in the context of VAR model. They focused on the predicted power of volume on Tokyo commodity futures market, and the result showed that volume did not have linear casual relationship with returns.

For Thai stock market, Chiradatesakunvong (2004) applied the VAR approach to examine the dynamic relations between trading volume and absolute returns and the relationship between trading volume and returns of stocks in the SET50 index during the period of 2002 to 2003. The study showed that the trading volume revealed 
additional information affecting stock prices. Chatrirat (2006) studied the role of trading volume in the volatilities of stocks included in the SET50 index using GARCH and EGARCH models, and found that the rate of information flow, as measured by trading volume, and its lags had an explanatory power on the variance of stock returns.

Up to now, there is no empirical study about trading volume and returns in Thai stock index futures market. This study will be the first one to provide evidence on how Thai stock index futures market responds to new information. In addition to investigating the contemporaneous relation through the GARCH and the GMM estimation, this study will also examine the dynamic relationship between trading volume and price volatility of futures market using the Granger causality test.

\section{Methodology}

\subsection{Theoretical framework}

There are many theories (hypotheses) that explain the relationship between returns and trading volume. The leading theories (hypotheses) among them are the "Mixture of Distribution Hypothesis (MDH)" and the "Sequential Information Arrival Hypothesis (SIA)".

Mixture of distribution hypothesis (MDH) developed by Clark (1973) assumes that information circulation in the market is contemporaneous. MDH suggests that the conditional variance of returns or change in price $(\triangle P)$ is an increasing function of the rate of information flow to the market and trading volume is also driven by the same information or news so trading volume and returns have contemporaneous positive relationship.

Sequential information arrival hypothesis (SIA) proposed by Copeland (1976) assumes that individuals shift their demand curves sequentially as new information is revealed to them (only one individual at a time), while trading volume is the positive function of the strength of new information which is the size of change in demand curve. Sequential information arrival hypothesis also predicts the positive relationship between trading volume and absolute returns. While both hypotheses suggest that trading volume has a positive correlation to returns volatility, MDH only implies a contemporaneous relationship but the SIA with dynamic relationship suggests that the past trading volume contains information for predicting current returns volatility and vice versa (McMillan \& Speight, 2002). To test the implications of both hypotheses, this study will investigate the contemporaneous relationship between trading volume and returns through the GARCH and GMM simultaneous equations, and also test whether the past trading volume (price) can be used to improve the future price (volume) prediction by using the Granger causality test in the context of VAR model.

\subsection{Estimation method}

Following Floros and Vougas (2007) and Ciner (2002), this study examined the contemporaneous relationship between returns (volatility) and trading volume using the GARCH model and estimated system of simultaneous equations using GMM approach, and also investigated whether information about trading volume is useful for predicting the price of SET50 index futures by the Granger causality test in the context of VAR model.

According to Floros and Vougas (2007), the variables in this study are defined as follows:

$$
R_{t}=\ln \left(\frac{F_{t}}{F_{t-1}}\right)
$$

where $R_{t}$ is the return of stock index futures at time $\mathrm{t}$ and $F_{t}$ is closing futures price at time $t$. 


$$
L N V O L_{t}=\ln \frac{V_{t}}{V_{t-1}}
$$

where $L N V O L_{t}$ is the daily return of trading volume and $V_{t}$ is trading volume.

\subsection{GARCH model}

Lamoureux and Lastrapes (1990) who investigated volume-volatility relationship by the GARCH model, suggested that under $\mathrm{MDH}$, daily returns are generated by the mixture of distributions with the rate of daily information arrival, as a stochastic mixing variable implies that when daily information arrival is assumed to be serially correlated, the variance of daily returns is heteroskedastic and positively related to information arrival. As the rate of information arrival cannot be observed directly, the trading volume will be used as a proxy. Lamoureux and Lastrapes (1990) argued that if the MDH is true, including trading volume into the variance equation as an explanatory variable will eliminate the significance and persistence (measured by the sum of coefficients of ARCH terms) of ARCH effect.

To investigate the relationship between returns and trading volume, the authors firstly estimate GARCH models for SET50 index futures returns and assume AR (1) in the mean equation to eliminate serial correlation problem in returns series. The number of lag $(p$ and $q)$ in $\operatorname{GARCH}(p, q)$ variance equation is determined according to the Akaike's information criteria (AIC).

$$
\begin{gathered}
R_{t}=\mu+a_{1} R_{t-1}+\varepsilon_{t} \\
\varepsilon_{t} \mid\left(\varepsilon_{t-1}, \varepsilon_{t-2}, \ldots\right) \sim N\left(0, \sigma_{t}^{2}\right) \\
\sigma_{t}^{2}=\omega+\sum_{i}^{p} \alpha_{i} \varepsilon_{t-i}^{2}+\sum_{i}^{q} \beta_{i} \sigma_{t-i}^{2}
\end{gathered}
$$

Then, the trading volume variable $\left(L N V O L_{t}\right)$ is included as an explanatory variable into equation (5).

$$
\sigma_{t}^{2}=\omega+\sum_{i}^{p} \alpha_{i} \varepsilon_{t-i}^{2}+\sum_{i}^{q} \beta_{i} \sigma_{t-i}^{2}+\gamma_{1} L N V O L_{t}
$$

According to Lamoureux and Lastrapes (1990), estimated parameter $\gamma_{1}$ from equation (6) should be significant and positive while the significance and persistence of ARCH terms should be eliminated.

Since Thai and emerging markets studies have found that the past information is useful due to lower level of efficiency and the Thai futures market is still in the early stage, the authors include the lag of trading volume into the variance equation (6) to investigate whether lagged volume has an explanatory power on the variance of returns;

$$
\sigma_{t}^{2}=\omega+\sum_{i}^{p} \alpha_{i} \varepsilon_{t-i}^{2}+\sum_{i}^{q} \beta_{i} \sigma_{t-i}^{2}+\gamma_{1} L N V O L_{t}+\gamma_{2} L N V O L_{t-1}
$$

For additional information about the SET50 index futures market, the authors also estimated a model to test whether there exists the positive relationship between trading volume and returns:

$$
R_{t}=\mu+a_{1} R_{t-1}+a_{2} L N V O L_{t}+\varepsilon_{t}
$$

We also will add the lag of trading volume into the equation (8) as follows:

$$
R_{t}=\mu+a_{1} R_{t-1}+a_{2} L N V O L_{t}+a_{3} L N V O L_{t-1}+\varepsilon_{t}
$$

However, according to "costly short sales hypothesis" (Karpoff, 1988), which predicted a zero correlation between trading volume and returns in the market where costs of taking long and short positions are symmetric, the authors expect that there is no statistically significant relationship between trading volume and returns in 
SET50 index futures.

\subsection{GMM system of equations}

Although GARCH model is useful for investigating the relation between trading volume and volatility and the existence of MDH, Foster (1995) indicated that using trading volume as a proxy of the information arrival to explain volatility of returns might cause simultaneity bias because the MDH also suggested that volume and volatility are the joint function of information flow which means that trading volume is not exogenous and the estimated model might be inconsistent.

To avoid simultaneity bias problem, Foster (1995) analyzed the relationship between trading volume and returns volatility through a system of equations with the generalized method of moment (GMM) estimation. The GMM estimation approach, with the instrument variable (IV) as an estimator, will control for the simultaneity bias and also heteroskedasticity in an error term.

Following Floros and Vougas (2007), the authors estimated the system of equations as:

$$
\begin{gathered}
\left|R_{t}\right|=\omega+a L N V O L_{t}+\gamma\left|R_{t-1}\right|+\varepsilon_{t} \\
L_{N V O L_{t}}=\phi+\lambda\left|R_{t}\right|+\mu L N V O L_{t-1}+\xi_{t}
\end{gathered}
$$

where $\left|R_{t}\right|$ is absolute returns which represent the volatility.

This model treats both $\left|R_{t}\right|$ and $L N V O L_{t}$ as endogenous variables, so estimating this system of equations by OLS will be inconsistent. Therefore, the generalized method of moment (GMM) with IV estimator is used to avoid any simultaneity bias.

\subsection{Granger causality test}

In addition to the examination of contemporaneous relationship between trading volume and volatility (absolute returns), this study also investigate the dynamic relationship as implied by Sequential information hypothesis. The Granger causality test in context of vector auto-regressive (VAR) model is used to test whether the information about trading volume could improve the prediction about futures price (returns). To perform the Granger causality test, the authors firstly estimated the VAR model for (absolute) returns and trading volume series. The VAR model will treat both absolute returns and trading volume as endogenous.

Estimated VAR model:

$$
\begin{gathered}
\left|R_{t}\right|=\gamma_{0}+\sum_{i=1}^{n} \gamma_{1} \text { LNVOL }_{t-i}+\sum_{i=1}^{n} \gamma_{2}\left|R_{t-i}\right|+\varepsilon_{|R|, t} \\
\text { NNVOL }_{t}=\alpha_{0}+\sum_{i=1}^{n} \alpha_{1} \text { LNVOL }_{t-i}+\sum_{i=1}^{n} \alpha_{2}\left|R_{t-i}\right|+\varepsilon_{L N V O L, t}
\end{gathered}
$$

The appropriate lag length of the model is determined by the Akaike's information criteria (AIC).

When VAR model is estimated, the Granger causality test is performed to investigate the casual relation between trading volume and absolute returns or in other words, to test whether past information of volatility $(|\mathrm{R}|)$ is useful to improve the prediction of trading volume and vice versa. The Granger causality test will test the null hypothesis that trading volume does not Granger cause volatility $(|R|)$, which will be rejected if the coefficient of past trading variables in VAR model of equation (12) are jointly significant and different from zero, and the null hypothesis that volatility $(|R|)$ does not Granger cause trading volume, which will be rejected if the coefficients of past volatility $(|R|)$ variables in VAR model of equation (13) are jointly significant and different from zero.

\subsection{Data}

This study uses daily closing prices and trading volume from SET-SMART-D from April 2006 to December 
2008 of SET50 futures contracts traded on TFEX. There are 4 series, of which delivery months are March, June, September and December. The total 653 observations are taken from nearest contracts due to trading pattern that the nearest contracts are most actively traded and volume is quite sparse in the far contracts. Daily trading volume is defined as the number of traded contracts during the day. Price of futures contract is index point multiplied by the contract multiplier which is 1,000 baht.

\section{Empirical results}

The summary statistics of SET50 index futures absolute returns and volume are reported in Table 1 and the result from unit root test is reported in Table 2.

Absolute returns and trading volume of SET50 index futures have positive skewness, and their kurtosis exceed 3. The statistics imply that the distributions of both series are skew to the right and leptokurtic (or peak relative to normal distribution). The high Jarque-Bera (J-B) statistics with zero $p$-value mean that the null hypothesis of normality is rejected at $1 \%$ significant level.

Table 1 Statistics for SET50 index futures (absolute returns and trading volume)

\begin{tabular}{|c|c|c|c|}
\hline & Absolute returns & \multicolumn{2}{|c|}{ Trading volume } \\
\hline Mean & 0.01471 & \multicolumn{2}{|c|}{4586.06} \\
\hline Median & 0.00952 & \multicolumn{2}{|c|}{3939.00} \\
\hline Maximum & 0.14376 & \multicolumn{2}{|c|}{20666.00} \\
\hline Minimum & 0.00000 & \multicolumn{2}{|c|}{36.00} \\
\hline Std. Dev. & 0.01662 & \multicolumn{2}{|c|}{3851.10} \\
\hline Skewness & 3.07050 & \multicolumn{2}{|c|}{1.21555} \\
\hline Kurtosis & 17.25863 & \multicolumn{2}{|c|}{4.54927} \\
\hline Jarque-Bera & 6557.762 & \multicolumn{2}{|c|}{226.113} \\
\hline Probability & $0.000 * * *$ & \multicolumn{2}{|c|}{$0.000 * * *$} \\
\hline \multicolumn{4}{|c|}{ Unit root tests for price and trading volume } \\
\hline & & Price & Volume \\
\hline \multirow[t]{3}{*}{ Test critical values: } & $1 \%$ level & -3.44015 & -3.44021 \\
\hline & $5 \%$ level & -2.86576 & -2.86578 \\
\hline & $10 \%$ level & -2.56907 & -2.56909 \\
\hline \multicolumn{4}{|c|}{ Augmented Dickey-Fuller test statistic } \\
\hline At level ADF & & -2.34745 & -2.86630 \\
\hline First diff. ADF & & -27.72560 & -17.07725 \\
\hline
\end{tabular}

Table 2 shows the results from the augmented Dickey-Fuller (ADF) test which is the stationary test for the series. The results show that the null hypothesis of unit root cannot be rejected at $10 \%$ and $1 \%$ significant level for futures price and trading volume respectively and suggest that both series are non-stationary at certain level. However, both series are stationary at the first difference (logarithmic returns of futures price and volume). As in the time series analysis, the variables should be transformed to be stationary to avoid spurious problem in model 
estimation, this study uses the first difference of futures price and trading volume or returns $\left(\ln \left(\mathrm{F}_{t} / \mathrm{F}_{\mathrm{t}-1}\right)\right)$ and LNVOL $\left(\ln \left(\mathrm{V}_{\mathrm{t}} / \mathrm{V}_{\mathrm{t}-1}\right)\right)$ to investigate the relationship between trading volume and price volatility.

Table 3 The results from GARCH models

\begin{tabular}{|c|c|c|c|c|c|}
\hline & Model A & Model B & Model C & Model D & Model E \\
\hline \multicolumn{6}{|c|}{ Mean equation } \\
\hline \multirow[t]{2}{*}{$\mu$} & 0.00094 & 0.00057 & 0.00058 & 0.00106 & 0.00106 \\
\hline & $(0.07570)^{*}$ & $(0.22130)$ & $(0.26200)$ & $(0.03750)^{* *}$ & $(0.04310)^{* *}$ \\
\hline \multirow[t]{2}{*}{$a_{1}$} & -0.04119 & -0.05198 & -0.00928 & -0.03506 & -0.03490 \\
\hline & $(0.34100)$ & $(0.17510)$ & $(0.83300)$ & $(0.43770)$ & $(0.43980)$ \\
\hline \multirow[t]{2}{*}{$\mathrm{a}_{2}$} & - & - & - & 0.00274 & 0.00271 \\
\hline & & & & $(0.01530)^{* *}$ & $(0.02010)^{* *}$ \\
\hline \multirow[t]{2}{*}{$\mathrm{a}_{3}$} & - & - & - & - & -0.00011 \\
\hline & & & & & $(0.93050)$ \\
\hline \multicolumn{6}{|c|}{ Variance equation } \\
\hline \multirow[t]{2}{*}{$\omega$} & 0.00001 & 0.00001 & 0.00010 & 0.00001 & 0.00001 \\
\hline & $(0.00200)^{* * *}$ & $(0.03900)^{* * *}$ & $(0.00000)^{* * *}$ & $(0.01020)^{* * *}$ & $(0.01040)^{* * *}$ \\
\hline \multirow[t]{2}{*}{$\alpha_{1}$} & 0.19718 & 0.18124 & 0.26326 & 0.21149 & 0.21172 \\
\hline & $(0.00000)^{* * *}$ & $(0.00000)^{* * *}$ & $(0.00000)^{* * *}$ & $(0.00000)^{* * *}$ & $(0.00000)^{* * *}$ \\
\hline \multirow[t]{2}{*}{$\alpha_{2}$} & 0.16655 & 0.26216 & 0.17939 & 0.18623 & 0.18598 \\
\hline & $(0.00010)^{* * *}$ & $(0.00000)^{* * *}$ & $(0.01210)^{* * *}$ & $(0.00020)^{* * *}$ & $(0.00020)^{* * *}$ \\
\hline \multirow[t]{2}{*}{$\beta_{1}$} & 0.32176 & 0.07776 & 0.30172 & 0.34391 & 0.34401 \\
\hline & $(0.00000)^{* * *}$ & $(0.23650)$ & $(0.01840)^{* * *}$ & $(0.00000)^{* * *}$ & $(0.00000)^{* * *}$ \\
\hline \multirow[t]{2}{*}{$\beta_{2}$} & -0.34692 & -0.03392 & -0.17608 & -0.34538 & -0.34529 \\
\hline & $(0.00000)^{* * *}$ & $(0.64270)$ & $(0.02450)^{* * *}$ & $(0.00000)^{* * *}$ & $(0.00000)^{* * *}$ \\
\hline \multirow[t]{2}{*}{$\beta_{3}$} & 0.65639 & 0.53326 & 0.21227 & 0.61013 & 0.61000 \\
\hline & $(0.00000)^{* * *}$ & $(0.00000)^{* * *}$ & $(0.00050)^{* * *}$ & $(0.00000)^{* * *}$ & $(0.00000)^{* * *}$ \\
\hline \multirow[t]{2}{*}{$\gamma_{1}$} & - & 0.00007 & 0.00011 & - & - \\
\hline & & $(0.00000)^{* * *}$ & $(0.00000)^{* * *}$ & & \\
\hline \multirow[t]{2}{*}{$\gamma_{2}$} & - & - & -0.00012 & - & - \\
\hline & & & $(0.00000)^{* * *}$ & & \\
\hline
\end{tabular}

Notes: $* * *, * * *$ indicate significance at $1 \%, 5 \%$ and $10 \%$.

Table 3 shows results from estimated GARCH models with the $p$-values in parentheses: Model A is standard GARCH (2,3) model which assume AR (1) in mean equation; Model B and model C show the results from including LNVOL and LNVOL with lagged (respectively) into variance equations of model $\mathrm{A}$ to investigate whether trading volume has an explanatory power on returns volatility; Model D and model E show the results from including LNVOL and LNVOL with lagged (respectively) in mean equation of model A to investigate the relationship between trading volume and returns.

Model A:

$$
R_{t}=\mu+a_{1} R_{t-1}+\varepsilon_{t}
$$




$$
\sigma_{t}^{2}=\omega+\sum_{i}^{p} \alpha_{i} \varepsilon_{t-i}^{2}+\sum_{i}^{q} \beta_{i} \sigma_{t-i}^{2}
$$

Model C:

$$
\sigma_{t}^{2}=\omega+\sum_{i}^{p} \alpha_{i} \varepsilon_{t-i}^{2}+\sum_{i}^{q} \beta_{i} \sigma_{t-i}^{2}+\gamma_{1} L N V O L_{t}
$$

$$
\begin{gathered}
R_{t}=\mu+a_{1} R_{t-1}+\varepsilon_{t} \\
\sigma_{t}^{2}=\omega+\sum_{i}^{p} \alpha_{i} \varepsilon_{t-i}^{2}+\sum_{i}^{q} \beta_{i} \sigma_{t-i}^{2}+\gamma_{1} L N V O L_{t}+\gamma_{2} L_{N V O L_{t-1}}
\end{gathered}
$$

Model E:

$$
\begin{gathered}
R_{t}=\mu+a_{1} R_{t-1}+a_{2}{ }^{L N V O L_{t}}+\varepsilon_{t} \\
\sigma_{t}^{2}=\omega+\sum_{i}^{p} \alpha_{i} \varepsilon_{t-i}^{2}+\sum_{i}^{q} \beta_{i} \sigma_{t-i}^{2}
\end{gathered}
$$

$$
\begin{gathered}
R_{t}=\mu+a_{1} R_{t-1}+a_{2} \text { LNVOL }_{t}+a_{3} \text { LNVOL }_{t-1}+\varepsilon_{t} \\
\sigma_{t}^{2}=\omega+\sum_{i}^{p} \alpha_{i} \varepsilon_{t-i}^{2}+\sum_{i}^{q} \beta_{i} \sigma_{t-i}^{2}
\end{gathered}
$$

To examine whether trading volume, as a proxy of the information arrival, can explain the persistence of volatility of returns as suggested by MDH and sequential information arrival hypothesis, this study follows the work of Floros and Vougas (2007) by estimating the GARCH model for SET50 index futures returns with AR(1) in mean equation to eliminate serial correlation of residual. The orders of ARCH and GARCH terms in variance equation equal to 2 and 3 which give the lowest Akaike's Information Criteria (AIC). The result of model $A$ confirms the significant GARCH effect in returns series. Model $B$ shows the result from including trading volume variable into variance equation. The result, consistent with Floros and Vougas (2007) result on FTSE/ASE-20 and Sharma, et al (1996), shows that trading volume has significant positive effect on returns volatility. Also, including trading volume into model can reduce significance and persistence of GARCH effect (persistence measured by sum of coefficients of ARCH terms), but not entirely eliminate the GARCH effect. This finding suggests that trading volume has an explanatory power on the GARCH effect of futures returns and has positive contemporaneous relationship to returns volatility which supports both MDH and SIA.

Then, this study extends the work of previous studies by including lagged trading volume into variance equation as Thai futures market is still in the early stage and may have lower level of efficiency, so past information is expected to be useful. The result from model $\mathrm{C}$ shows that past trading volume also has a significant effect in explaining GARCH effect of futures returns which implies market inefficiency in some degree.

The study also investigates the relationship between trading volume and returns by including trading volume and the lag of trading volume into the mean equation of model $\mathrm{A}$, the result is shown in model $\mathrm{D}$ and model $\mathrm{E}$ respectively. The results from model $\mathrm{D}$ and model $\mathrm{E}$ show that only current trading volume has positive significant relation to returns. The significant positive contemporaneous relationship between trading volume and returns in the result, inconsistent with previous evidences that showed no correlation in futures market, seems to reject the "costly short sales hypothesis" (Karpoff, 1988) which predicts zero correlation between trading volume and returns in the market that the cost of taking long and short position is symmetric, as in futures market. This result might imply the inefficiency of SET50 index futures market in the sense that this evidence breaks down the 
futures market's efficiency assumption of symmetric relationship which represents the characteristic of the market where agents have linear unbiased responses to information (Foster, 1995).

Table 4 shows the result from the system of equations estimated by GMM and provides GMM estimation result for the system of equations which shows the relations between trading volume and absolute returns as in equation (10) and equation (11).

$$
\begin{gathered}
\left|R_{t}\right|=\omega+a L N V O L_{t}+\gamma\left|R_{t-1}\right|+\varepsilon_{t} \\
L N V O L_{t}=\phi+\lambda\left|R_{t}\right|+\mu L N V O L_{t-1}+\xi_{t}
\end{gathered}
$$

Consistent with Ciner (2002) and Gwilym, et al (1999), the coefficients of $\mathrm{LNVOL}_{\mathrm{t}}$ in equation (10) and $\left|R_{t}\right|$ in equation (11) are statistically significant and show the positive contemporaneous relation between trading volume and absolute returns, which supports both MDH and SIA. The coefficients of $\left|R_{t-1}\right|$ and $L N V O L_{t-1}$ are also statistically significant which suggest that past information of trading volume and volatility can be used to explain current trading volume and volatility. This could be evidence that the market is inefficient.

Table 4 Relations between trading volume and absolute returns from GMM estimation

\begin{tabular}{clc}
\hline & Dependent variable: $\left|\mathrm{R}_{\mathrm{t}}\right|$ & \\
\hline & Instrument list: $\left|\mathrm{R}_{\mathrm{t}-1}\right| \mathrm{LNVOL}_{\mathrm{t}-1}$ & \\
\hline Variable & Coefficient & $0.0000^{* * *}$ \\
\hline$\omega$ & 0.00967 & $0.0000^{* * *}$ \\
$\mathrm{LNVOL}$ & 0.00897 & $0.0000^{* * *}$ \\
$\left|\mathrm{R}_{\mathrm{t}-1}\right|$ & 0.35297 & \\
\hline & Dependent variable: $\mathrm{LNVOL}^{*}$ & \\
\hline & Instrument list: $\left|\mathrm{R}_{\mathrm{t}-1}\right| \mathrm{LNVOL}_{\mathrm{t}-1}$ & $p$-value \\
\hline Variable & Coefficient & $0.0000^{* * *}$ \\
\hline$\varphi$ & -0.10260 & $0.0000^{* * *}$ \\
\hline $\mathrm{R}_{\mathrm{t}} \mid$ & 5.46000 & $0.0000^{* * *}$
\end{tabular}

Notes: $* * *, * *, *$ indicate significance at $1 \%, 5 \%$ and $10 \%$ respectively.

Table 5 The result from Granger causality test

\begin{tabular}{ccc}
\hline Granger causality test & LNVOL-Abs returns & LNVOL-Returns \\
\hline LNVOL $\rightarrow \mathrm{R}$ & $13.5408^{* *}$ & 0.81442 \\
$\mathrm{R} \rightarrow \mathrm{LNVOL}$ & $1.8655^{*}$ & 0.8943 \\
\hline
\end{tabular}

Notes: ***,**,* indicate significance at $1 \%, 5 \%$ and $10 \%$ respectively. This table provides the result from Granger causality test within the context of VAR models with 6 lag lengths which is the most appropriate lag length based on AIC criteria. The number in table is $\chi^{2}$ (Wald) Statistics for null hypothesis of no Granger causality. The asterisks show the statistically significance to reject null hypothesis.

To investigate whether we can use the past information of trading volume and returns to improve the predictions of another, the authors firstly estimated the VAR models with 6 lags based on the Akaike's information criteria (AIC). Then, the Granger causality test is estimated by Wald test for joint significance of all other lagged endogenous variables.

The result shows that the null hypothesis of no Granger causality is statistically rejected at $5 \%$ and $10 \%$ 
significant level for trading volume to absolute returns and for absolute returns to trading volume respectively. This shows bi-directional causality between trading volume and absolute returns or in other words, the past information of trading volume can be used to improve the predictions of futures price volatility and vice versa. This finding is also consistent with the SIA and previous studies such as Gwilym, et al (1999).

However, the results for trading volume and returns, consistent with Ciner (2002), suggest that the causal relations do not exist in both directions. This result implies that the past information of trading volume is not useful to help improving the prediction of price movement in Thai stock index futures market.

\section{Conclusion}

This study investigates the relationship between trading volume and returns volatility in SET50 index futures using the data during April 2006 to December 2008. To examine both contemporaneous and dynamic relations between trading volume and returns volatility, the authors incorporate 3 models used by previous researches, which are the GARCH model, the GMM system of equations and the Granger causality test in the context of VAR model.

The results from both GARCH models and GMM system of equations show the significant positive contemporaneous relation between trading volume and returns volatility, consistent with previous researches and support both mixture of distribution hypothesis (MDH) and sequential information arrival hypothesis (SIA). Moreover, the results from the GARCH suggest that lagged trading volume (not included in previous studies) is significant in explaining returns volatility, consistent with the GMM result which shows that the lag of trading volume and returns volatility can explain current trading volume and returns volatility. These results also imply market inefficiency in some degree.

The Granger causality test in the context of VAR model shows bi-directional causal relations between trading volume and returns volatility which support dynamic relation implied by Sequential Information Arrival hypothesis. This finding implies that information in SET50 index futures market is sequentially disseminated and we can use past information of trading volume and returns volatility to improve prediction of current returns volatility.

These findings could be useful for regulators that they should take into account that the higher market volatility that will come along with higher trading volume when any policies are implemented and could affect the trading volume. Moreover, the finding that the past information of trading volume is useful to improve the prediction of price volatility suggests that regulators and traders could use past information of trading volume in tracking and monitoring the market volatility level (for regulators) as well as the investment risk (for traders) in the TFEX.

References:

Chatrirat, C.. (2006). Test of information-based variance model: Evidence from the SET. (Independent study, Master of Science in Finance Program, Thammasat University).

Chiradatesakumvong, S.. (2004). Does trading volume convey information in stock price? Evidence from the SET. (Independent study, Master of Science in Finance Program, Thammasat University).

Ciner, C.. (2002). Information content of volume: An investigation of Tokyo commodity futures markets. Pacific-Basin Finance Journal, 10, 201-215.

Clark, P.. (1973). Subordinated stochastic process model with finite variance for speculative prices. Econometrica, 41, $135-155$.

(to be continued on Page 35) 